\title{
Horta escolar: laboratório vivo para o ensino de ciências e biologia
}

\section{School garden: living laboratory for science and biology teaching}

\author{
Lidiane Figueiredo dos Santos ${ }^{1}$; Fabíola Aparecida Pimentel ${ }^{2}$; Regina Aparecida de Figueiredo \\ Santos $^{3}$; Sabrina de Sousa Proêza ${ }^{4}$
}

\begin{abstract}
RESUMO: O ensino de Ciências e Biologia torna o cidadão mais crítico acerca dos fenômenos naturais que os cercam, assim, é importante criar práticas pedagógicas que ensinem essas disciplinas de forma lúdica, unindo teoria e prática. No entanto, as escolas públicas não apresentam uma estrutura laboratorial que atenda a essa demanda. Assim, surge a necessidade dos professores adotarem práticas alternativas. Dentre essas práticas tem-se a implantação de hortas na escola, alternativa que tem se mostrado eficiente no processo de ensino-aprendizagem.
\end{abstract}

PALAVRAS-CHAVE: Agroecologia; Educação; Escola Pública.

\begin{abstract}
Teaching Science and Biology makes citizens more critical about the natural phenomena that surround them, so it is important to create pedagogical practices that teach these disciplines in a playful way, combining theory and practice. However, public schools do not have a laboratory structure that meets this demand. Thus, there is a need for teachers to adopt alternative practices. Among these practices, there is the implementation of vegetable gardens at school, an alternative that has been shown to be efficient in the teaching-learning process.
\end{abstract}

KEYWORDS: Agroecology; Education; Public school.

\section{INTRODUÇÃO}

\footnotetext{
${ }^{1}$ Doutora em Biotecnologia Vegetal pela Universidade Estadual do Norte Fluminense Darcy Ribeiro (UENF), Campos dos Goytacazes, RJ, Brasil. Professora da Rede Estadual de Minas Gerais, Brasil. E-mail:

lidianefigueiredosantos@hotmail.com

${ }^{2}$ Mestre em Produção Vegetal pela Universidade Estadual do Norte Fluminense Darcy Ribeiro (UENF), Campos dos Goytacazes, RJ, Brasil. Professora da Rede Estadual de Minas Gerais, Brasil. E-mail: fabiolaap65@ @otmail.com

3 Pós-Graduada em Supervisão, Orientação e Inspeção Escolar pelo Instituto Superior Tupy. Professora da Escola Municipal Nossa Senhora de Fátima, s/n, Zona Rural, 36.880-000, Muriaé, MG, Brasil. E-mail: reginafigueiredo98@yahoo.com.br

${ }^{4}$ Mestre em Políticas Públicas pela Faculdade Unida de Vitória (UNIDA), Vitória, ES, Brasil. Professora da Rede Estadual do Espírito Santo, Brasil. E-mail: sabrinaproeza@ hotmail.com 
O ensino de Ciências e Biologia sofreu importantes evoluções de acordo com as necessidades sociais, econômicas e ambientais. Com isso, as práticas pedagógicas e os objetivos dessas disciplinas passaram por uma "metamorfose", desde sua implementação na educação brasileira.

Diante da importância das disciplinas de Ciências e Biologia, torna-se necessária a criação e aplicação de práticas pedagógicas com recursos laboratoriais, uma vez que elas despertam nos alunos interesse, curiosidade, participação e aprendizagem significativa, quando comparado ao modelo tradicional de ensino.

No entanto, as escolas públicas carecem de recursos laboratoriais que auxiliem a interdisciplinaridade dos conteúdos e contribuam para a construção do conhecimento dos alunos (CRUZ, 2009; SILVA et al., 2017a). Como consequência da ausência desse recurso nas escolas, temse a dificuldade de aprendizagem dos alunos acerca de temas complexos e abstratos na área de ciências e biologia. Temas que poderiam ser facilmente compreendidos a partir de aulas práticas e atividades lúdicas (CRUZ, 2009; SILVA et al., 2017a).

Em meio a este cenário, surge a necessidade de se criar práticas pedagógicas que supram a ausência de laboratórios. Dentre essas práticas, a implementação de hortas nas escolas é uma proposta que vem apresentando bons resultados. A horta no ambiente escolar funciona como um "laboratório vivo", oportunizando trabalhar diversos temas dentro das disciplinas ciências e biologia, dentre eles meio ambiente, agroecologia e alimentação saudável (FINGER e MOURA, 2013).

O objetivo deste trabalho é demonstrar que a horta escolar pode ser considerada um laboratório vivo para o ensino de ciências e biologia, além de apresentar as etapas para implementação de uma horta no ambiente escolar.

\section{METODOLOGIA}

Para a elaboração do presente trabalho, utilizou-se como metodologia a revisão de literatura. Em um primeiro momento, investigou-se a história do ensino de ciências e biologia e a problemática da carência de laboratórios nas escolas. Em seguida, foi realizada uma pesquisa bibliográfica sobre as metodologias utilizadas na implantação da horta escolar e sua importância como um local alternativo para aulas práticas, com base em resultados de projetos já realizados dentro dessa temática. 


\section{HISTÓRIA DO ENSINO DE CIÊNCIAS E BIOLOGIA}

O ensino de ciências compreende pesquisas voltadas para a área de Ciências da Natureza e, atualmente, é trabalhada nas escolas a partir das seguintes disciplinas: 1) Ciências: trabalhada no ensino fundamental ( $6^{\circ}$ ao $9^{\circ}$ ano) e que inclui conteúdos das disciplinas física, química e biologia; 2) Biologia: trabalhada no Ensino Médio, com conteúdos específicos dessa área.

A evolução do ensino de ciências se deu, historicamente, de acordo com desenvolvimento da sociedade. Ciências e biologia foram incluídas na educação básica brasileira a partir de 1890 (ROSA e ROSA, 2012). Durante a metade do século XIX, Rui Barbosa lutou pela inclusão da disciplina "ciências" como conteúdo curricular das escolas brasileiras para todos os níveis, em virtude dos avanços tecnológicos. No entanto, ela só passou a ser incorporada nos currículos escolares na metade do século XX e não de forma obrigatória. Até 1945, o ensino de ciências caminhava junto às necessidades geradas pelo início da industrialização (ROSA e ROSA, 2012). Nos anos 60, essa disciplina foi considerada neutra, onde a qualidade estava relacionada com a quantidade de conteúdos transmitidos (KRASILCHIK, 1992). A partir de 1970, o ensino de ciências passa a ter o papel de tornar o cidadão atuante e crítico diante das tecnologias e dos problemas ambientais que surgem neste período (SANTOS et al., 2011).

Uma vez inseridas no currículo escolar, ciências e biologia precisam agora cativar os estudantes. Segundo Nicola e Paniz (2016), a educação atual ainda apresenta características do ensino tradicional, onde o professor apenas transmite informações e o aluno é sujeito passivo do processo de aprendizagem, o que resulta em falta de interesse pelas disciplinas de ciências e biologia. Assim, surge a necessidade de se criar práticas pedagógicas que não se limitem apenas ao quadro e giz, mas que dialoguem com o cotidiano do aluno e que despertem o interesse pela natureza e suas formas de vida (NICOLA e PANIZ, 2016).

Atualmente, o ensino de ciências e biologia de forma prática tem sido afetado pela falta de laboratórios nas escolas públicas de educação básica, instituições historicamente afetadas falta de investimento do poder público. Além disso, a história da educação brasileira é marcada por constantes reformas curriculares realizadas pelos órgãos governamentais. Essa instabilidade no discurso sobre quais disciplinas permanecem ou são eliminadas/reduzidas do currículo escolar dificulta e atrasa investimentos na área da educação. Consequentemente, isso exige dos professores a busca por alternativas que supram diversas falhas do sistema educacional, como a ausência de laboratórios nas escolas (PIMENTA e RODRIGUES, 2011). 


\section{CARÊNCIA DE LABORATÓRIOS NAS ESCOLAS PÚBLICAS DE EDUCAÇÃO BÁSICA}

Desde o século XIX, a existência de laboratórios nas escolas representa um importante meio de instrução na área das ciências, recebendo papel central e distintivo (BLOSSER, 1990). A experimentação assistida no ensino de física, química e biologia pode proporcionar aos alunos habilidades, conceitos e atitudes (BLOSSER, 1990), contribuindo para a construção de seu conhecimento (SILVA et al., 2017a). Além disso, laboratórios didáticos auxiliam na interdisciplinaridade e na transdisciplinaridade dos conteúdos (CRUZ, 2009).

Segundo a Lei de Diretrizes e Bases da Educação (LDB), Artigo 35, Inciso IV, "É essencial a compreensão dos fundamentos científico-tecnológicos dos processos produtivos, relacionando a teoria com a prática, no ensino de cada disciplina". No entanto, observa-se no Brasil precariedade na aplicação desse inciso, uma vez que as escolas públicas não conseguem iniciar e/ou manter as atividades laboratoriais constantemente, por outro lado, percebe-se uma maior utilização desses espaços por escolas privadas (BEREZUK e INADA, 2010). Segundo o último Censo Escolar, realizado na rede pública e privada, somente $25,4 \%$ das escolas de ensino fundamental apresentam laboratórios de ciências (INEP, 2017). No ensino médio, cerca de 51,3\% das escolas possuem essa estrutura (INEP, 2017). Na rede pública de ensino o cenário é ainda mais precário, onde apenas 8,19\% das escolas contam com laboratórios (TODOS PELA EDUCAÇÃO, 2017).

Dentre os fatores que contribuem para a não realização e/ou baixa adesão de atividades práticas por alunos e professores da rede pública, está a ausência de um espaço físico para o laboratório e de materiais para seu funcionamento (ANDRADE e COSTA, 2016). A falta de recursos financeiros destinados à criação e manutenção dos laboratórios precisa ser resolvida para garantir um melhor ensino de ciências e biologia (SILVA et al., 2011). Além disso, em muitos casos, existe a necessidade de adaptação da sala de aula em laboratório, o que coloca em risco a segurança de alunos e professores, já que esse espaço improvisado nem sempre atende aos requisitos de segurança (DELPINO e KRUGER, 1997).

A privação dos alunos à prática laboratorial é fator determinante para a qualidade do ensino e aprendizagem (ADEYEMI, 2008). Reflexos da ausência de laboratórios nas escolas de educação básica podem ser observados na classificação do Brasil no Programa Internacional de Avaliação de Alunos (Pisa) na disciplina ciências, em 2015, onde o país ficou em $63^{\circ}$ lugar entre os 70 países participantes do programa (CASTRO, 2017).

Apesar das dificuldades existentes no ensino de ciências e biologia pela ausência de laboratórios na maioria das escolas, é possível adotar práticas alternativas e que contribuam para a experimentação. Na falta de um laboratório, o professor pode substituir equipamentos sofisticados e 
onerosos por materiais de baixo custo e fácil acesso (SILVA et al., 2017a), além de poder utilizar "laboratórios a céu aberto" para as aulas, como hortas.

\section{QUAL ALTERNATIVA PARA SUPRIR A AUSÊNCIA DE LABORATÓRIOS NAS ESCOLAS PÚBLICAS?}

Uma alternativa para suprir a ausência de laboratório nas escolas é utilização de hortas como "laboratório vivo", como "laboratório a céu aberto" (SILVA et al., 2013). De acordo com Pimenta e Rodrigues (2011), a horta funciona como um laboratório onde os recursos são vivos, o que permite uma ampla forma de trabalhar. Além disso, a horta pode ser utilizada como ferramenta no ensino de educação ambiental, agroecologia e educação alimentar dentro das disciplinas de ciências e biologia (FERREIRA e CARDOSO, 2005). Vale lembrar que a horta escolar trabalha a interdisciplinaridade e a transdisciplinaridade dos conteúdos, podendo ser utilizada como recurso didático por outras disciplinas da grade curricular (FERREIRA e CARDOSO, 2005).

A horta na escola fornece alimentação saudável aos alunos e permite trabalhar diversas temáticas ambientais, tais como: preservação do meio ambiente, animais e água (CARVALHO e SILVA, 2014). Também permite trabalhar diversos outros temas comuns à área de ciências e biologia, o que inclui: cadeia alimentar, horticultura orgânica, propriedades física e químicas do solo e água, assim como vegetação e compostagem (QUEIROZ et al., 2009).

A horta inserida no ambiente escolar permite abordar a problemática dos agrotóxicos, que podem afetar negativamente o ambiente e a saúde das pessoas (FINGER e MOURA, 2013). Além disso, diversos são os trabalhos que mostram a confecção de canteiros com garrafas pets ou pneus (SILVA e LIMA, 2013; COSTA et al, 2015), o que permite conscientizar os alunos da importância dos 3 Rs: Reduzir, Reutilizar e Reciclar. Já nas escolas urbanas, este “laboratório vivo" permite aos alunos um contato maior com a natureza.

A metodologia de implementação da horta escolar se baseia, primeiramente, na explicação do projeto aos alunos, enfatizando a relevância da construção da horta em coletividade, com participação ativa de todos. Feito isso, o próximo passo consiste no levantamento das principais espécies vegetais cultivadas na região onde a escola está inserida. Desse modo, é possível associar temas presentes na grade escolar, como clima, solo e alimentação saudável com o cultivo de certas hortaliças (SANTOS e SANTOS, 2016; SANTOS et al., 2018).

Após o levantamento das hortaliças cultivadas na região, os alunos devem estudar essas espécies, a fim de conhecer seu papel nutricional, importância para a saúde e modo de cultivo, além 
de se informarem sobre os riscos do uso de agrotóxicos em cultivos convencionais da espécie. Desta forma, é possível trabalhar a agroecologia, ciência com potencial de redesenhar agroecossistemas mais sustentáveis através da utilização de práticas alternativas aos agrotóxicos e fertilizantes nitrogenados (ALTIERI, 1999).

Para tornar o projeto interessante aos alunos, professores que já implementam o projeto horta ou que dominam técnicas agroecológicas são convidados pela escola para ministrarem palestras, cursos e ensinarem novas práticas (SANTOS e SANTOS, 2016). Em seguida, os alunos são levados à horta para a confecção de canteiros e plantio das hortaliças. Os alunos participantes são divididos em grupos, de forma que cada um fique responsável por uma atividade. Para avaliar participação e aprendizagem dos alunos são solicitados relatórios ao final de cada prática (SANTOS e SANTOS, 2016).

Diferentes estudos têm comprovado o sucesso da horta escolar no processo de ensinoaprendizagem (QUEIROZ et al., 2009; CARVALHO e SILVA, 2014; SANTOS e SANTOS, 2016; SILVA et al., 2017; SANTOS et al., 2018). Em uma escola do campo da Zona da Mata de Minas Gerais, um projeto denominado "Horta Viva: além dos muros da escola", foi desenvolvido em parceria com famílias agrícolas da região. Neste projeto a horta é "viva" no sentido de "sem agrotóxicos", onde os alunos do pré ao quinto ano utilizam práticas agroecológicas no cultivo de verduras que irão enriquecer a merenda escolar. Essas práticas "agroecológicas" não agridem o meio ambiente e fornecem um alimento saudável aos estudantes. Na escola, a professora ensina essas práticas aos alunos, que os repassam aos agricultores familiares da comunidade, que cultivam hortaliças. Dentre as alternativas estudadas, tem-se o Bokashi, um adubo orgânico natural que contém micro e macronutrientes de forma balanceada, e o EM, inoculante a base de micro-organismos capturados da natureza (SANTOS e SANTOS, 2016; SANTOS et al., 2018).

Vale ressaltar que a horta escolar também pode estar presente no ambiente urbano. Um exemplo disso é o projeto "Semeando ações agroecológicas na escola", realizado por alunos do ensino médio em uma escola estadual, localizada na cidade de Muriaé/MG. Nesse projeto, além dos alunos cultivarem alimentos sustentáveis e aprenderem, de forma lúdica, os conteúdos da sala de aula, eles divulgam esses trabalhos em eventos científicos, realizados em instituições de nível superior (SILVA et al., 2017). Resultados similares foram encontrados por Pimentel et al. (2020) ao implantar uma horta agroecológica na Escola Estadual Joaquim Bartholomeu Pedrosa, localizada no município de Fervedouro/MG. Nessa escola alunos do sexto ao nono ano do Ensino Fundamental são responsáveis pelo plantio e irrigação das hortaliças, além de produzirem fertilizantes naturais, como o EM. Como resultado do projeto, as hortaliças produzidas na escola são utilizadas na merenda escolar.

Além dos resultados citados, outros trabalhos já demonstraram os resultados positivos que uma horta escolar pode oferecer aos alunos. Conforme Cancelier et al. (2020), a horta tornou o 
ambiente escolar mais atrativo, os alunos se envolveram nas atividades com entusiasmo, compreenderam com maior facilidade a relação entre produção de alimentos saudáveis e educação ambiental, além de se tornarem mais críticos em relação à importância da proteção ambiental. A criação de uma horta também aproximou família e escola (CANCELIER et al., 2020). De acordo com Martinez e Hlenka (2017) e Pimentel et al. (2020), os resultados dos seus projetos demonstraram que a horta, como instrumento pedagógico, contribuiu para a assimilação dos conteúdos, estimulou a curiosidade dos alunos, além disso, todos aprenderam a importância do companheirismo e da cooperação.

\section{CONCLUSÃO}

A horta inserida no ambiente escolar pode ser o "laboratório vivo" que possibilita a realização de diversas atividades pedagógicas em educação ambiental e alimentar ao unir teoria e prática, promovendo a conscientização dos alunos acerca da produção agroecológica, problemática dos agrotóxicos, utilização de práticas sustentáveis, proteção da natureza e compreensão de temas da grade curricular. Esse espaço também melhora as condições nutricionais das refeições dos alunos e estreita relações sociais entre os membros da comunidade escolar. A participação de alunos de escolas públicas rurais e urbanas em projetos dessa natureza contribui para a formação dos mesmos e permite que estes já tenham, desde cedo, contato com o "mundo científico" e saibam que são capazes de fazer parte dele.

\section{REFERÊNCIAS}

ADEYEMI, T. O. Science Laboratories and the Quality of Output from Secondary Schools in Ondo State, Nigeria. Asian Journal of Information Management, Janeiro, 2008 v. 2, p. 23-30, 2008.

ALTIERI, M. Bases científicas para uma agricultura sustentável. Nordan Comunidad: Montevidéo, 1999.

ANDRADE, T. M. I; COSTA, M. D. O Laboratório de Ciências e a Realidade dos Docentes das Escolas Estaduais de São Carlos - SP. Química nova escola, v. 38, n. 3, p. 208-2014, 2016.

BEREZUK, P. A.; INADA, P. Avaliação dos laboratórios de ciências e biologia das escolas públicas e particulares de Maringá, Estado do Paraná. Acta Scientiarum Human and Social Sciences, v. 32, n. 2, p. 207-215, 2010. 
BLOSSER, P. The role of the laboratory in science teaching. Research Matters-to the Science Teacher, v. 9001, 1990. Disponível em: https://www.narst.org/publications/research/labs.cfm. Acesso em: 11 de ago. 2017.

CASTRO, F. Escassez de laboratórios de ciências nas escolas brasileiras limita interesse dos alunos pela física. Revista Educação, v. 239, 2017.

CANCELIER, J. W; BELING, H.M; FACCO, J. A. Educação ambiental e o papel da horta escolar na educação básica. Revista de Geografia (Recife), v. 37, n. 2, 2020.

COSTA, C. A. G; SOUZA, J. T. A; PEREIRA, D. D. Horta escolar: alternativa para promover educação ambiental e desenvolvimento sustentável no Cariri Paraibano. Polêm!ca, v. 15, n. 3, p. 0109, 2015.

CRUZ, J. B. Laboratórios. Brasília: Universidade de Brasília. 2009.

DELPINO, J. C; KRÜGER, V. Segurança no Laboratório. Porto Alegre: CECIRS, 1997.

FERREIRA, S. C. M.; CARDOSO, W. C. Horta escolar: um laboratório vivo. Universidade Federal do Piauí, 2005.

FINGER, C. Y. U; MOURA, J. D. P. A produção de mudas e horta escolar orgânica para a sustentabilidade socioambiental. Cadernos PDE, v 1. P. 24, 2013.

INEP. Censo Escolar da Educação Básica 2016 - Notas estatísticas, 2017. Disponível em: http://download.inep.gov.br/educacao_basica/censo_escolar/notas_estatisticas/2017/notas_estatistic as_censo_escolar_da_educacao_basica_2016.pdf. Acesso em: 11 de ago. 2017.

KRASILCHIK, M. Caminhos do Ensino de Ciências no Brasil. Em Aberto, v. 11, n. 55, p. 3-8, 1992.

MARTINEZ, I. C. P. A.; HLENKA, V. Horta escolar como recurso pedagógico. Revista Eletrônica Científica Inovação e Tecnologia, v. 8, n. 16, 2017.

NICOLA, J. A; PANIZ, C. A importância da utilização de diferentes recursos didáticos no ensino de biologia. Revista. NEaD-Unesp, v. 2, n. 1, p. 355-381, 2016.

PIMENTA, J. C.; RODRIGUES, K. S. M. Projeto horta escola: ações de educação ambiental na escola centro promocional todos os santos de Goiânia (GO). II SEAT - Simpósio de Educação Ambiental e Transdisciplinaridade UFG/IESA/NUPEAT - Goiânia, maio de 2011. Disponível em: https://nupeat.iesa.ufg.br/up/52/o/29_Horta_na_escola.pdf. Acesso em: 11 de ago. 2017.

PIMENTEL, F. A.; SANTOS, L. F.; SANTOS, R. A. F.; SILVA, T. L.; LINO, K. A. Implementação de horta orgânica em escola pública. X Simpósio Brasileiro de Agropecuária Sustentável e VII Congresso Internacional de Agropecuária Sustentável - Viçosa, setembro de 2020. Disponível em: https://www.simbras-as.com.br/anais-de-resumos-expandidos-2020/. Acesso em: 24 de ago. 2020.

ROSA, C. W; R, A. B. O ensino de ciências (Física) no Brasil: da história às novas orientações educacionais. Revista Iberoamericana de Educación. Revista Ibero-americana de Educação, v. 58, n. 2, 2012. 
SANTOS, A. C; CANEVER, C. F; GIASSE, M. G; FROTA, P. R. O. A importância do ensino de ciências na percepção de alunos de escolas da rede pública municipal de Criciúma-SC. Revista Univap, v. 17, n. 30, p. 68-80, 2011.

SANTOS, L. F.; SANTOS, R. A. F. Horta viva: além dos muros da escola. Revista ELO - Diálogos em Extensão, v. 05, n. 1, 2016.

SANTOS, L. F.; SANTOS, R. A. F; PIMENTEL, F. A. Produção agroecológica de morangos: do campo à sala de aula. Cadernos de Agroecologia, v. 13, n. 1, 2018.

SILVA, A. F.; FERREIRA, J. H.; VIERA C. A. O ensino de ciências no ensino fundamental e médio: reflexões e perspectivas sobre a educação transformadora. Revista Exitus, v. 7, n. 2, p. 283-304, 2017a.

SILVA, E. V; LIMA, R. M. Os desafios da escola pública paranaense na perspectiva do professor PDE. Cadernos PDE, v. 1, p. 32, 2013.

SILVA, F. S. S.; MORAES, L. J. O; CUNHA, I. P. R. Dificuldades dos professores de biologia em ministrar aulas práticas em escolas públicas e privadas do munícipio de Imperatriz-MA. Revista UNI, v. 1, p. 135-149, 2011.

SILVA, J. D. S.; OLIVEIRA, W. S.; BRAGA, J. A. V.; MORELLI, A. B.; SANTOS, L. F. Projeto Horta: semeando ações agroecológicas na escola. In: Simpósio de Ciências da FASM, 3, 2017b, Muriaé. Anais...Muriaé: FASM, 2017.

SILVA, L. H. de A.; ZANON, L. B. Ensino de Ciências: fundamentos e abordagens. São Paulo: UNIMEP, 2000.

TODOS PELA EDUCAÇÃO. Menos de 5\% das escolas tem infraestrutura adequada ao PNE. Disponível em: http://www.todospelaeducacao.org.br/reportagens-tpe/30192/menos-de-5-dasescolas-tem-infraestrutura-adequada-ao-pne/. Acesso em: 20 mar. 2017. 